\title{
Preparation and Evaluation of Controlled Release Parenteral Nanosuspensions of Anastrazole
}

\author{
Rajakumar Devara ${ }^{1}$, Mohammed Habibuddin ${ }^{2}$, Kiran Thadkala $^{3}$, \\ Jithan Aukunuru* ${ }^{4 *}$ \\ ${ }^{1,3}$ Mother Teresa College of Pharmacy, Ghatkesar, Hyderabad, India. \\ ${ }^{2}$ ShadanCollege of Pharmacy, Peerancheru, Hyderabad, India. \\ ${ }^{4}$ Mankind Research Center, Manesar, Haryana, India.
}

\begin{abstract}
Anastrazole is a class of medication called non steroidal aromatase inhibitors. It works by decreasing the amount of estrogen in the body makes this can slow or stop the growth of many types of breast cancer cells that need estrogen to grow. As it is having poor water solubility and poor wettability, anastrazole leads to poor dissolution and hence shows poor bioavailability. The present study is aimed at increasing dissolution rate/solubility of drug and its sustained release property of drug, used as parenteral nanosuspension. Nanosuspension formulations of anastrazole were prepared by anti-solvent solvent precipitation technique. The formulations were characterized by scanning electron microscopy, zeta potential, powder X-ray diffractometry, saturation solubility and in-vitro drug release. The evaluation studies were performed by using optimum formulation based on the particle size and saturation solubility, formulations were selected and further studies with the formulation were conducted. As a result of this method, it was found that the dissolution rate and saturation solubility of the nanosuspension formulation was significantly higher compared to the conventional suspension formulation. Further, the optimum formulation controls the drug release for 24 hours. Therefore, in this study a parenteral nanosuspension formulation of anastrazole were successfully developed and evaluated. The formulation is intended for controlled release delivery of the drug after i.v. administration with enhanced $\mathrm{C}_{\max }$. The formulation can be successfully used in breast cancer as it reduces the production of estrogen after intravenous administration.
\end{abstract}

Keywords : Nanosuspension, anastrazole, tween-80, solvent-antisolvent precipitation method.

\section{Introduction}

Anastrazole is a class-IV (Low permeability and low solubility) classified under biopharmaceutical classification system with low solubility and low permeability. Anastrazole is soluble in organic solvents such as ethanol, methanol and completely insoluble in water. Poor solubility leads to poor release rate, therefore to enhance the dissolution rate of the drug, different techniques have been employed in particle size reduction by micronization which is a conventional technique and nanosuspension which is a novel technique where

International Journal of PharmTech Research, 2018,11(2): 96-107.

DOI: http://dx.doi.org/10.20902/IJPTR.2018.11201 
saturation solubility has been achieved compared with enhanced the dissolution release rate ${ }^{1,2}$. The parenteral administration route is the most effective and common form of delivery for active drug substances with metabolic bioavailabilities drug for which the bioavailability is limited by high first pass metabolism effect of other physicochemical limitation and for drugs with a narrow therapeutic index. For this reason, whatever drug delivery technology that can reduce the total number of injection throughout the drug therapy period will be truly advantageous not only in terms of compliance, but also for potential to improve the quality of the therapy. Such reduction in frequency of drug dosing is achieved, in practice, by the use of specific formulation technologies that guarantee the release of the active drug substance happens in a slow and predictable manner ${ }^{3,4}$. For several drugs, depending on the dose, it may be possible to reduce the injection frequency from daily to once or twice monthly or even less frequently. In addition to improving patient comfort, less frequent injection of drugs in the form of depot formulation smoothes out the plasma concentration time profiles by eliminating the peaks and valleys. Such smoothing out of the plasma profiles has the potential to not only boost the therapeutic benefit but also to reduce unwanted events side effects. The release can either be continuous or pulsatile depending on the structure of the device and the polymer characteristics, continuous release profiles are suitable to generate on 'infusion like' plasma level time profile in the systemic circulation without the necessity of hospitalization. A nanosuspension is a submicron colloidal dispersion of drug particles which are stabilized by surfactants ${ }^{5,6}$. A pharmaceutical nanosuspension is defined as very finely dispersed solid drug particles in an aqueous vehicle for either oral and topical use or parenteral and pulmonary administration. The particle size distribution of the solid particles in nanosuspension is usually less than one micron with an average particle size ranging between 200 and 600nm.In nanosuspension technology, the drug is maintained in the required crystalline state with reduced particle size, leading to an increased dissolution rate and therefore improved bioavailability ${ }^{7,8}$. An increase in the dissolution rate of micronized particles (particle size $<10 \mu \mathrm{m}$ ) is related to an increase in the surface area and consequently the dissolution velocity. Nanosized particles can increase solution velocity and saturation solubility because of the vapor pressure effect. In addition, the diffusional distance on the surface of drug nanoparticles is decreased, thus leading to an increased concentration gradient ${ }^{5}$. The increases in surface area and concentration gradient lead to a much more pronounced increase in the dissolution velocity as compared to a micronized product. Furthermore, the saturation solubility is increased as well. Another possible explanation for the increased saturation solubility is the creation of high energy surfaces when disrupting the more or less ideal drug microcrystals to nanoparticles ${ }^{9,10}$. Dissolution experiments can be performed to quantify the increase in the saturation solubility of a drug when formulated into a nanosuspension. The stability of the particles obtained in the nanosuspension is attributed to their uniform particle size which is created by various manufacturing processes. The absence of particles with large differences in their size in nanosuspension prevents the existence of different saturation solubility's and concentration gradients, consequently preventing the ostwald ripening effect ${ }^{11,}{ }^{12}$. Ostwald ripening is responsible for crystal growth and subsequently formation of micro particles. It is caused by a difference in dissolution pressure/saturation solubility between small and large particles. Molecules diffuse from the higher concentration area around small particles which have higher saturation solubility to an area around larger particles possessing a lower drug concentration. This leads to the formation of a supersaturated solution around the large particles and consequently to drug crystallization and growth of the large particles ${ }^{13,14}$.

\section{Materials and Methods}

Anastrazole is obtained as a gift sample from yucca enterprises, mumbai, india. Ethanol, tween 80 and methanol are from SD fine chemicals limited. All the other ingredients used were of analytical grade.

\section{Preparation of anastrazole nanosuspensions:}

Anastrazole nanosuspension was prepared by solvent-antisolvent precipitation method. Required quantity of anastrazole was weighed and dissolved in appropriate quantity of ethanol.Tween 80 in required quantities of distilled water was dissolved in a $250 \mathrm{ml}$ Buchner flask.Ethanol was used as a solvent and tween 80 as a surfactant to stabilize the nanosuspension formulation. Media 1 is added to media 2 drop wise with a constant stirring on a magnetic stirrer using a butterfly syringe. Vacuum was applied by placing paper on Buchner flask while stirring till the solvent evaporates. Product was filtered and dried at room temperature in a desiccator over night.Finally the product was filtered and centrifuged at $7000 \mathrm{rpm}$ for $10 \mathrm{~min}$. Particle size of drug nanosuspension after bath sonication mixing was measured. The drug nanosuspension was freeze dried. Depending on the average particle size the selected batches were freeze dried to obtain dry powder. When the dried form is reconstituted in an aqueous system, it may be redispersed to achieve its original particle size. The 
redispersibility of dried nanoparticles depends on the parameters of the freeze drying process. In this study, an apparatus with a freezing rate gradient was used to systematically investigate the effect of cryoprotectants on the redispersibility of cryoprotectants on the redispersibility of nanoparticles as a function of freezing rate. Sucrose, lactose, mannitol, and polyethylene glycol were used as cryoprotectants for a nanosuspension. A fast freezing rate and a high cryoprotectant concentration were generally favored $15,16,17,18,19,20$.

Table no: 1 Different batches of Anastrazole nanosuspension preparations

\begin{tabular}{|l|l|l|l|l|l|l|l|l|}
\hline Formulation & F- 1 & F- 2 & F- 3 & F- 4 & F- 5 & F- 6 & F- 7 & F-8 \\
\hline Anastrazole & $100 \mathrm{mg}$ & $100 \mathrm{mg}$ & $100 \mathrm{mg}$ & $100 \mathrm{mg}$ & $100 \mathrm{mg}$ & $100 \mathrm{mg}$ & $100 \mathrm{mg}$ & $100 \mathrm{mg}$ \\
\hline Ethanol & $25 \mathrm{ml}$ & $5 \mathrm{ml}$ & $5 \mathrm{ml}$ & $5 \mathrm{ml}$ & $5 \mathrm{ml}$ & $5 \mathrm{ml}$ & $5 \mathrm{ml}$ & $10 \mathrm{ml}$ \\
\hline $\begin{array}{l}\text { Distilled } \\
\text { water }\end{array}$ & $50 \mathrm{ml}$ & $50 \mathrm{ml}$ & $25 \mathrm{ml}$ & $10 \mathrm{ml}$ & $10 \mathrm{ml}$ & $10 \mathrm{ml}$ & $10 \mathrm{ml}$ & $5 \mathrm{ml}$ \\
\hline Tween 80 & $0.5 \mathrm{ml}$ & $0.5 \mathrm{ml}$ & $0.5 \mathrm{ml}$ & $0.5 \mathrm{ml}$ & $0.25 \mathrm{ml}$ & $0.75 \mathrm{ml}$ & $1.0 \mathrm{ml}$ & $0.5 \mathrm{ml}$ \\
\hline
\end{tabular}

Characterization of Nanosuspension ${ }^{21,22,23,24}$

Particle size analysis:

The mean particle size was determined by using optical microscope. In this method 250 particles size was determined by using stage micro meter and the average particle size was determined.

\section{Scanning Electron Microscopy:}

In order to examine the particle surface morphology and shape, Scanning Electron Microscopy (SEM) was used. A concentrated aqueous suspension was spread over a slab and dried under vacuum. The sample was shadowed in a cathodic evaporator with gold layer $20 \mathrm{~nm}$ thick. Photographs were taken using a JSM-5200 Scanning Electron Microscope (Tokyo, Japan) operated at $20 \mathrm{kV}$.

\section{Zeta Potential:}

The zeta potential was used to measure of the electric charge at the surface of the particles, indicating the physical stability of colloidal systems. In this study, the Zeta Potential was assessed by determining the electrophoretic mobility of the particles. The zeta potential was measured using a Zetasizer Nano ZS (Malvern Instruments, Malvern, UK). Samples were diluted with the respective original dispersion medium which provides information regarding the thickned of the diffuse layer. Diluted nanosuspension was added to the sample cell (quartz cuvette) and was put into the sample holder unit and measured. The higher the measured zeta potential, better was the physical long-term stability of the dispersion.

\section{Saturation Solubility:}

Saturation solubility is defined as the maximum quantity of a compound (solute) that can be dissolved in a certain quantity of a specific solvent at a specified temperature. The saturation solubility of the prepared nanosuspension, oral suspension and the pure drug were done by stirring on magnetic stirrer for $48 \mathrm{hrs}$ in distilled water. The nanosuspension powder was dispersed in $10 \mathrm{ml}$ of distilled water, kept for magnetic stirring for $48 \mathrm{hrs}$. Then $1.5 \mathrm{ml}$ of nanosuspension was filled into centrifugation tube and centrifuged at $25000 \mathrm{rpm}$ for $30 \mathrm{~min}$ (Remiindusrties centrifuge). Supernatant was filtered and analyzed spectrophotometrically using UVvisible spectrophotometer (UV- Shimadzu) at $221 \mathrm{~nm}$ after suitable dilution with phosphate buffer (pH 7.4) containing Tween 80 , which was used as blank. The pure drug was dispersed in $10 \mathrm{ml}$ of water. The prepared oral suspension was kept for magnetic stirring for $48 \mathrm{hrs}$. Then $1.5 \mathrm{ml}$ of it was filled into centrifugation tube and centrifuged at $25000 \mathrm{rpm}$ for 30 minutes (Remi indusrties centrifuge). Supernatant was filtered and analyzed spectrophotometrically using UV-visible spectrophotometer (UV-Shimadzu) at $221 \mathrm{~nm}$ after suitable dilution with phosphate buffer ( $\mathrm{pH}$ 7.4) containing tween 80, which was used as blank.

\section{Powder X-Ray Diffraction (PXRD) analysis:}

The drug crystalline state in the polymer sample was evaluated by Powder X-Ray Diffraction (PXRD) analysis. X-ray spectra were recorded with X'Pert-PRO multipurpose X-Ray diffractometer (PANalytical, 
Tokyo, Japan) using Ni-filtered, $\mathrm{Cu}$ Ka radiation, a voltage of $45 \mathrm{kV}$, and a current of $40 \mathrm{~mA}$ with a scintillation counter. The instrument was operated in the continuous scanning speed of $4^{\circ} / \mathrm{min}$ over a $2 \theta$ range of $5^{\circ}$ to $40^{\circ}$. The samples were grinded using a wedgwood mortar and pestle, placed into the cavity of an aluminum sample holder and packed smoothly using a glass slide.

\section{In-vitro drug release:}

In-vitro dissolution studies of samples were carried out using USP apparatus II paddle method by dispersed powder technique. Accurately weighed samples were added to $500 \mathrm{ml}$ of buffer media (Phosphate buffer $\mathrm{pH} 7.4$ ) at $37+0.5^{\circ} \mathrm{C}$ and stirred at $50 \mathrm{rpm}$. An aliquot of $10 \mathrm{ml}$ was withdrawn at different time intervals. The solid particles were prevented from pipetting by withdrawing the sample through a pipette fitted with a cotton plug. An equal volume of fresh dissolution medium was immediately replaced. The filtered samples were assayed spectrophotometrically at $221 \mathrm{~nm}$ by blank correction method as reported under the section. Phosphate buffer $\mathrm{pH} 7.4$ was used for in-vitro dissolution studies. The dissolution of nanosuspension was compared with the dissolution of equivalent amount of the oral suspension and pure drug.

\section{Results and Discussion}

Preformulation study for Anastrazole has been performed to know the drug physical properties so as to design it to a suitable formulation. Anastrazole is a class -IV (Low solubility and low permeability) classified under BCS Classification with low solubility and low permeability. Poor solubility leads to poor dissolution, therefore to enhance the dissolution rate of the drug, different techniques have been employed in the present study such as particle size reduction by nanosuspensions which is a novel technique where saturation solubility has been achieved compared to micronization, and formation of inclusion complexes by cyclodextrins which is a conventional technique, which also proved to enhance the dissolution rate, additionally use of surfactant which is commonly employed technique to enhance the solubility of the drug which improves dissolution rate and thereby enhances the bioavailability. The saturation solubility of the pure drug in phosphate bufferpH7.4 was found to be $0.39 \mathrm{mg} / \mathrm{ml}$. The saturation solubility of the nanosuspension F-6 in phosphate buffer pH7.4 was found to be $3.9 \mu \mathrm{g} / \mathrm{ml}$. The mean particle size was determined by using optical microscopy. The average particle size was found to be $0.34 \mu, 0.72 \mu$ and $0.81 \mu$ respectively. It was observed that by increasing the concentration of surfactant reduces the particle size in the formulation.

Table no: 2 Different batches of Anastrozole nanosuspension preparation with particle size

\begin{tabular}{|l|l|l|l|l|l|l|l|l|}
\hline Formulation & \multicolumn{1}{|c|}{ F1 } & F2 & F3 & F4 & F5 & \multicolumn{1}{|c|}{ F6 } & F7 & F8 \\
\hline Anastrozole & $100 \mathrm{mg}$ & $100 \mathrm{mg}$ & $100 \mathrm{mg}$ & $100 \mathrm{mg}$ & $100 \mathrm{mg}$ & $\mathbf{1 0 0 m g}$ & $100 \mathrm{mg}$ & $100 \mathrm{mg}$ \\
\hline Ethanol & $25 \mathrm{ml}$ & $5 \mathrm{ml}$ & $5 \mathrm{ml}$ & $5 \mathrm{ml}$ & $5 \mathrm{ml}$ & $\mathbf{5 m l}$ & $5 \mathrm{ml}$ & $10 \mathrm{ml}$ \\
\hline Distilled water & $50 \mathrm{ml}$ & $50 \mathrm{ml}$ & $25 \mathrm{ml}$ & $10 \mathrm{ml}$ & $10 \mathrm{ml}$ & $\mathbf{1 0 m l}$ & $10 \mathrm{ml}$ & $5 \mathrm{ml}$ \\
\hline Tween 80 & $0.5 \mathrm{ml}$ & $0.5 \mathrm{ml}$ & $0.5 \mathrm{ml}$ & $1 \mathrm{ml}$ & $1.5 \mathrm{ml}$ & $\mathbf{2 m l}$ & $0.5 \mathrm{ml}$ & $0.5 \mathrm{ml}$ \\
\hline $\begin{array}{l}\text { Average } \\
\text { particle size }\end{array}$ & $3.19 \mu$ & $3.61 \mu$ & $2.21 \mu$ & $0.59 \mu$ & $0.68 \mu$ & $\mathbf{0 . 3 4} \boldsymbol{\mu}$ & $0.72 \mu$ & $0.81 \mu$ \\
\hline
\end{tabular}

The results of in-vitro release studies were performed and the formulation F-6 is selected for further studies as it has average particle size of $0.34 \mu$ given in table 2 and saturation solubility was found to be 3.9 $\mu \mathrm{g} / \mathrm{ml}$.SEMwas used to determine the from the figure 1 and 2 surface morphology was visualized it was founed to be spherical, smooth, wavy and free flowing and concluded that the average particle size was found to be in a nano range i.e.,from $96.9 \mathrm{~nm}$ to $186 \mathrm{~nm}$ and that there is a size reduction of particles. Zeta size has been determined by zetasizer and reported as $212.5 \mathrm{~nm}$ from figure 3.The zeta potential and charge of the nanosuspension were evaluated by measuring the zeta potential of the nanosuspension by the malvern zeta sizer. The zeta potential of the optimized formulation F-6 was found to be-41.9mV from figure 4.XRPD was used to investigate the physical nature of the encapsulated drug, the powder X-ray. XRPD was used for analysis of a variety of transformations during pharmaceutical processing and storage such and degree of hydration. From the figures 5 and 6 , XRPD graphs it was observed that the crystallanity of the drug was changed in the nanosuspension. The peaks obtained for pure drug was very clear and sharp the intensity of the peaks was very high when compared to peaks of anastrazole nanosuspension. Reduction in the peak intensity indicates the change in crystal structure. From this we can conclude, that there was reduction in the crystallanity and change 
into amorphous structures as polymorphic transformations, alterations in crystallanity, changes in state. The state of drug has changed from one form to another form so there is change in drug solid state property from crystalline to amorphous. Drug-excipient interaction studies were performed for pure drug and optimed formulations were determined based on the FTIR spectra given in the figures 7 and 8 . The FTIR spectra of pure drug, physical mixture and nanosuspensions were compared to check any interactions between the drug and polymer or change in the positions of the functional group of the drug. There is no shift in peak of dug in the formulation. Hence there is no drug and excipient incompatibility problem. From the figures 9and 10, shows DSC thermograms of pure drug powder and optimized nanosuspension formulation respectively. Pure drug powder showed melting thermogram at which corresponds to its melting point and its thermogram in formulation was observed. From thermograms, it was concluded that the drug has been changed its physical structure in formulation thus concluded that there is change in physical state of drug in the formulation and change in drug solid state property from crystalline to amorphous. The results of drug release were expressed in terms of $\%$ drug dissolved as the function of time. The data obtained revealed that the onset of dissolution of pure anastrazole was (1.0\% in $5 \mathrm{~min}$ ) and (45\% in $24 \mathrm{hrs}$ ). From the data obtained it was observed that there was an increase in $\%$ drug release (3.2 \% in $5 \mathrm{~min}$ ) and $\left(78.8 \mathrm{in} 24^{\text {th }} \mathrm{hr}\right.$ ) with the optimized nanosuspension. It clearly indicates that nanosuspension formulation has been successful technique to improve the dissolution rate thereby enhancing the controlled release after intravenous (i.v.) administration with enhanced $\mathrm{C}_{\max }$. The optimized formulation (F-6) has an average particle size of $0.345 \mu$ and saturation solubility was found to be $3.9 \mu \mathrm{g} / \mathrm{ml}$. The nanosuspension formulation is good for breast cancer.

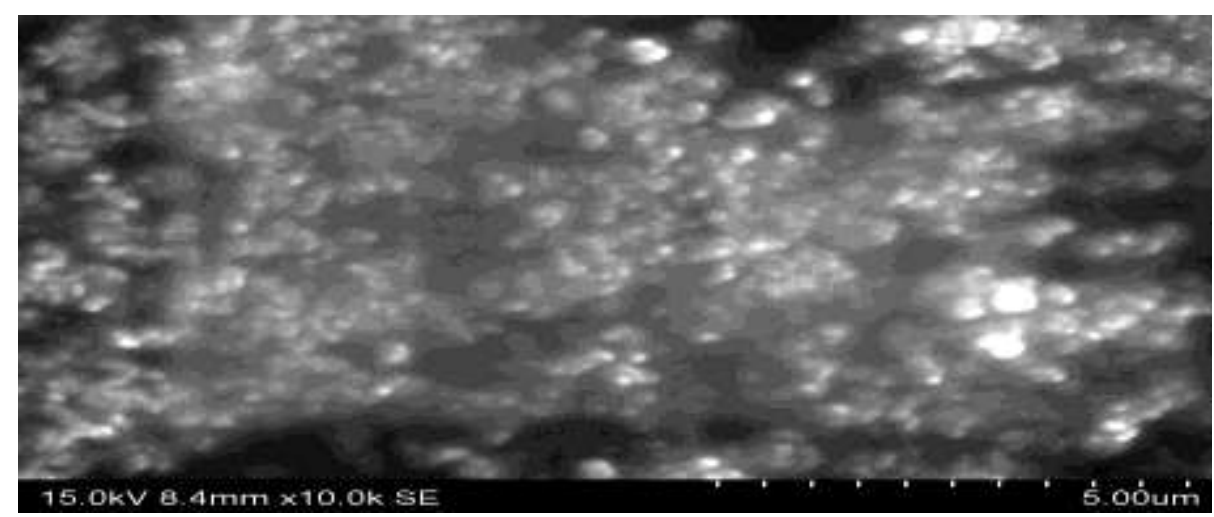

Figure no: 1 SEM picture and surface mrphology anastrazole nanosuspensions in spherical shape

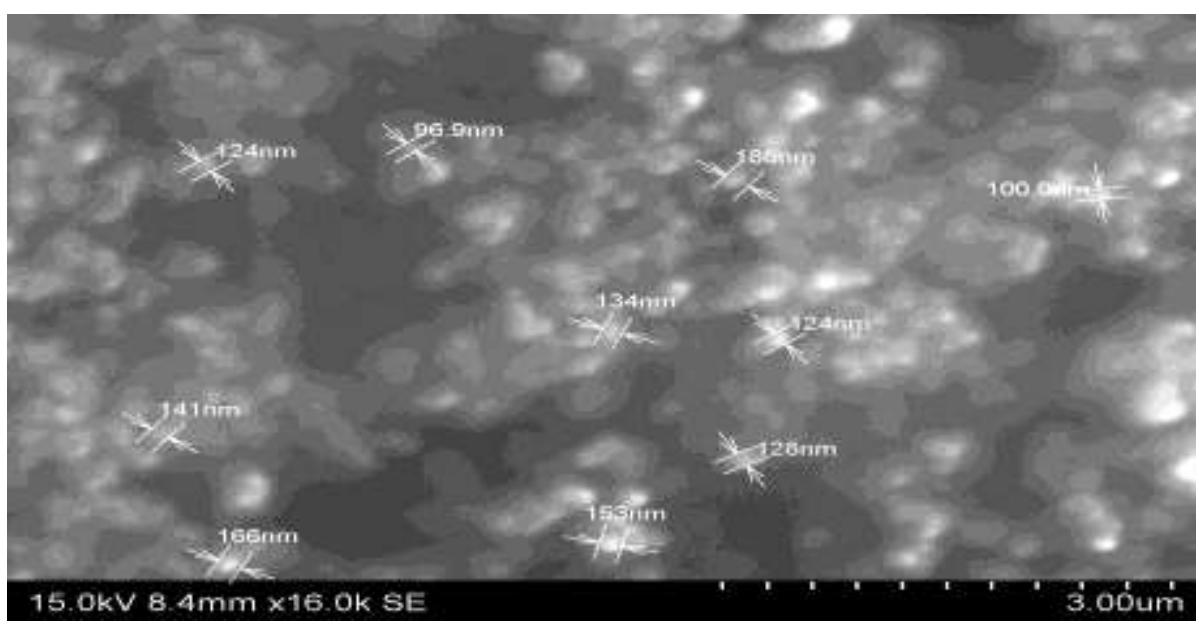

Figure no: 2 SEM picture of anastrazole particles in nano range 


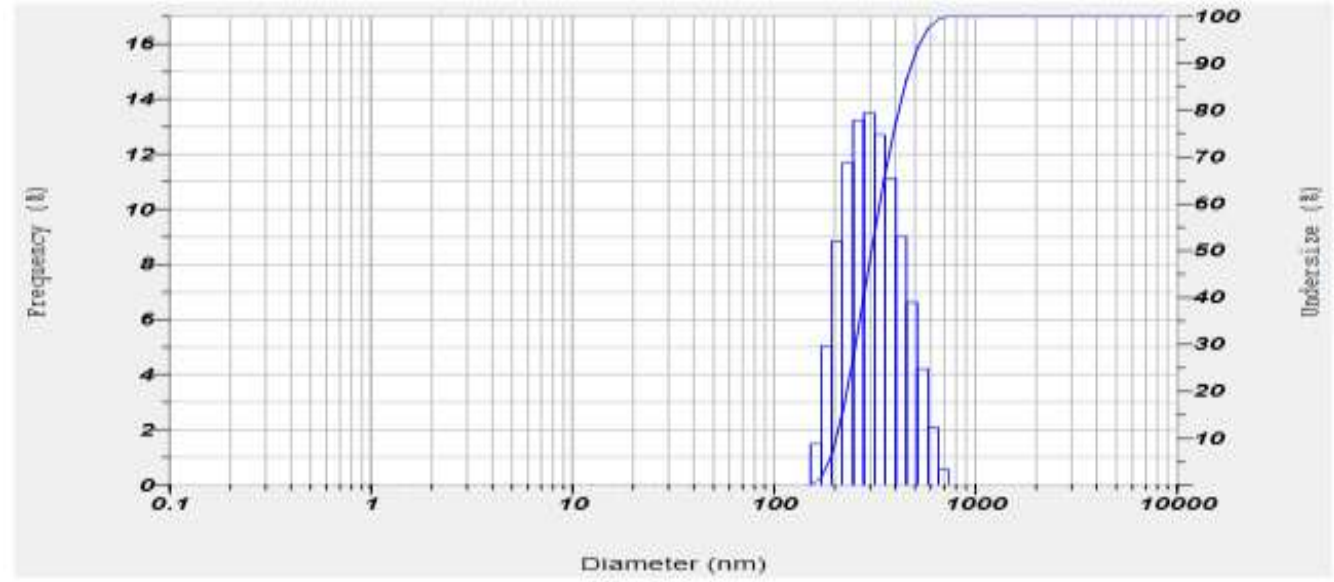

Figure no: 3 Zeta size of anastrazolenanosuspension

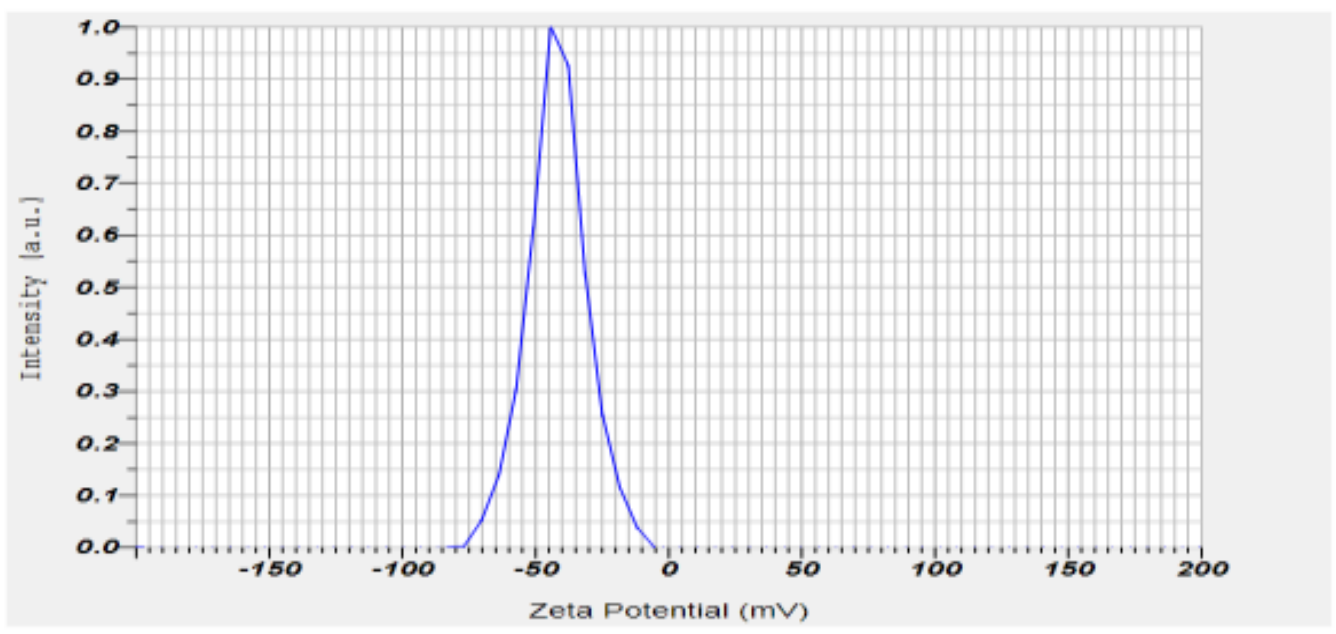

Figure no: 4 Zeta potential of anastrozole nanosuspension

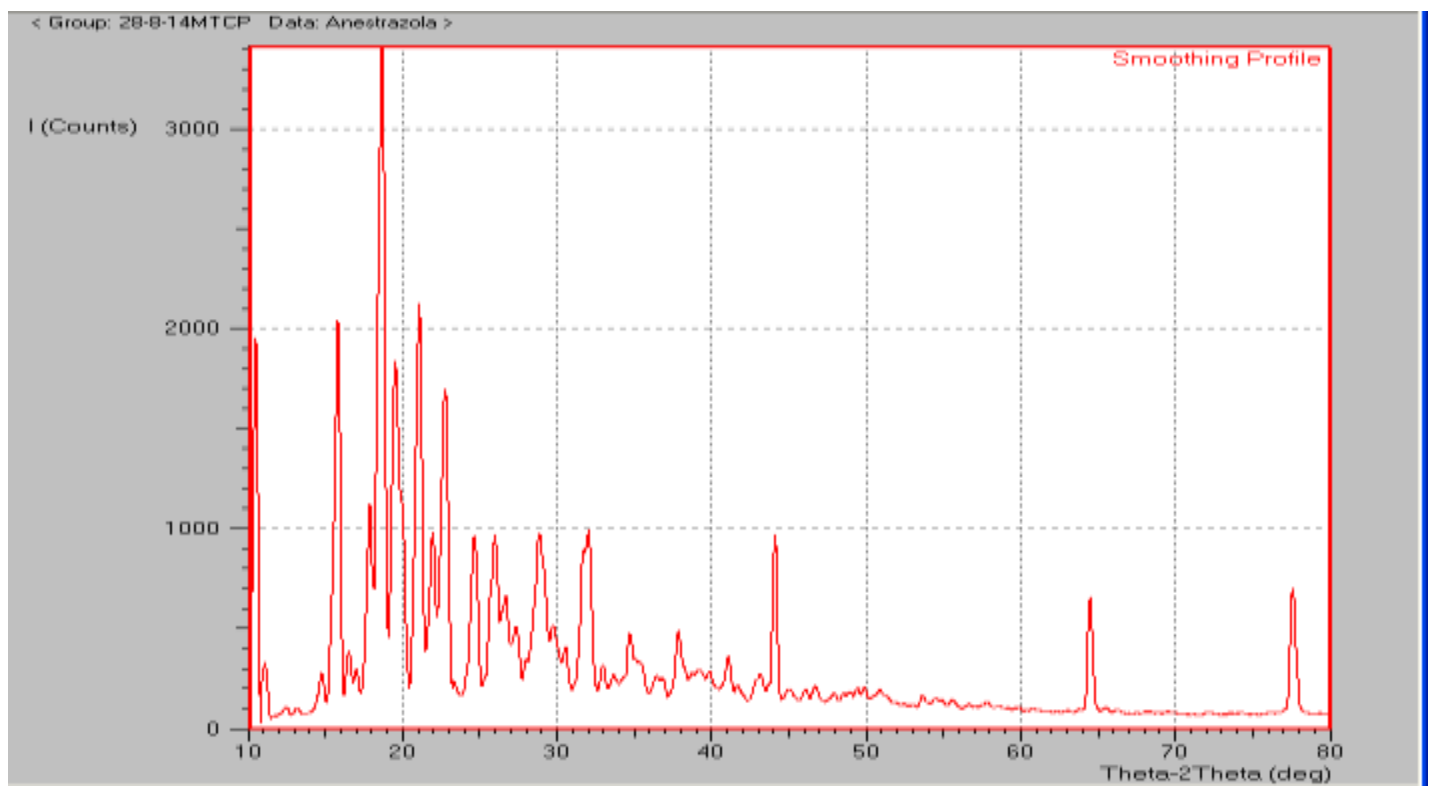

Figure no: 5 XRPD graph of anastrazole drug 


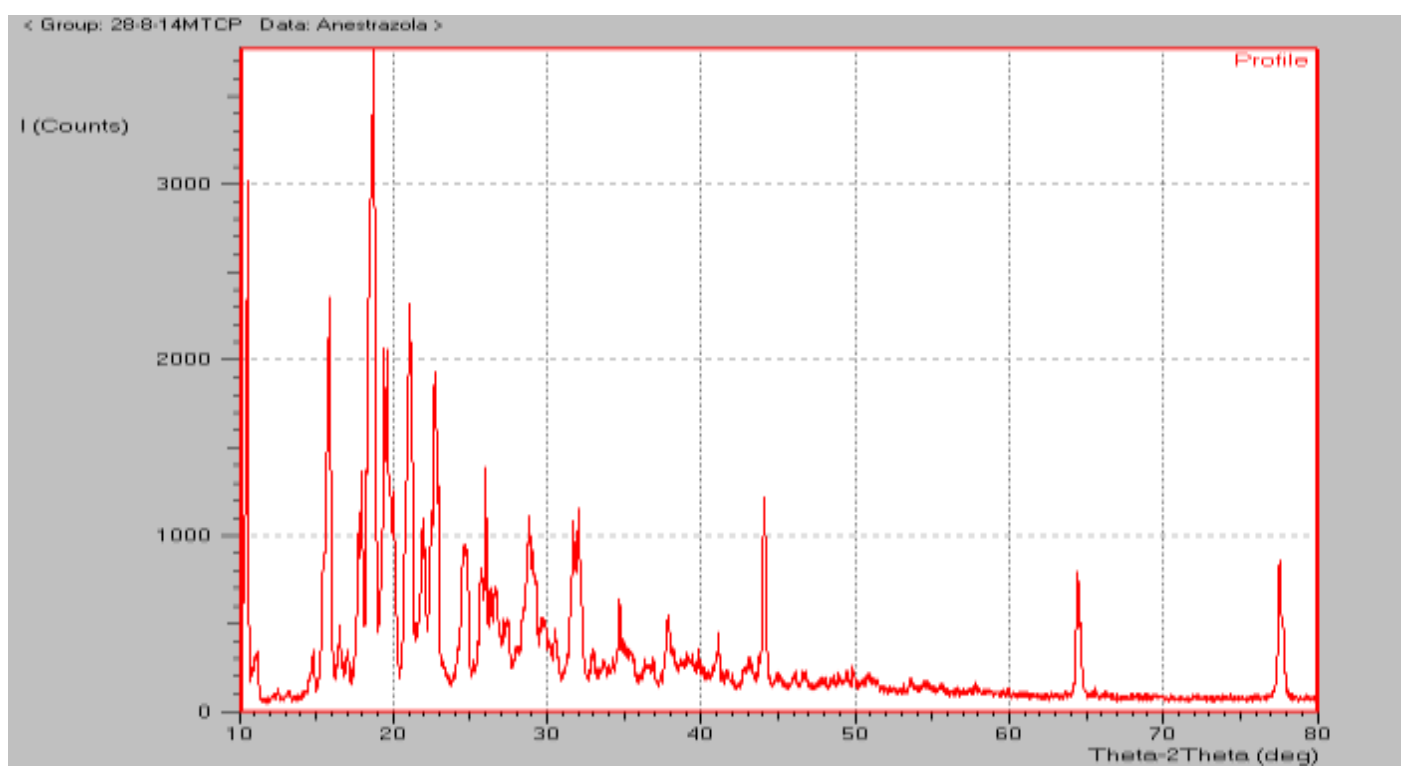

Figure no: 6 XRPD graph of anastrazole nanosuspension (F6)

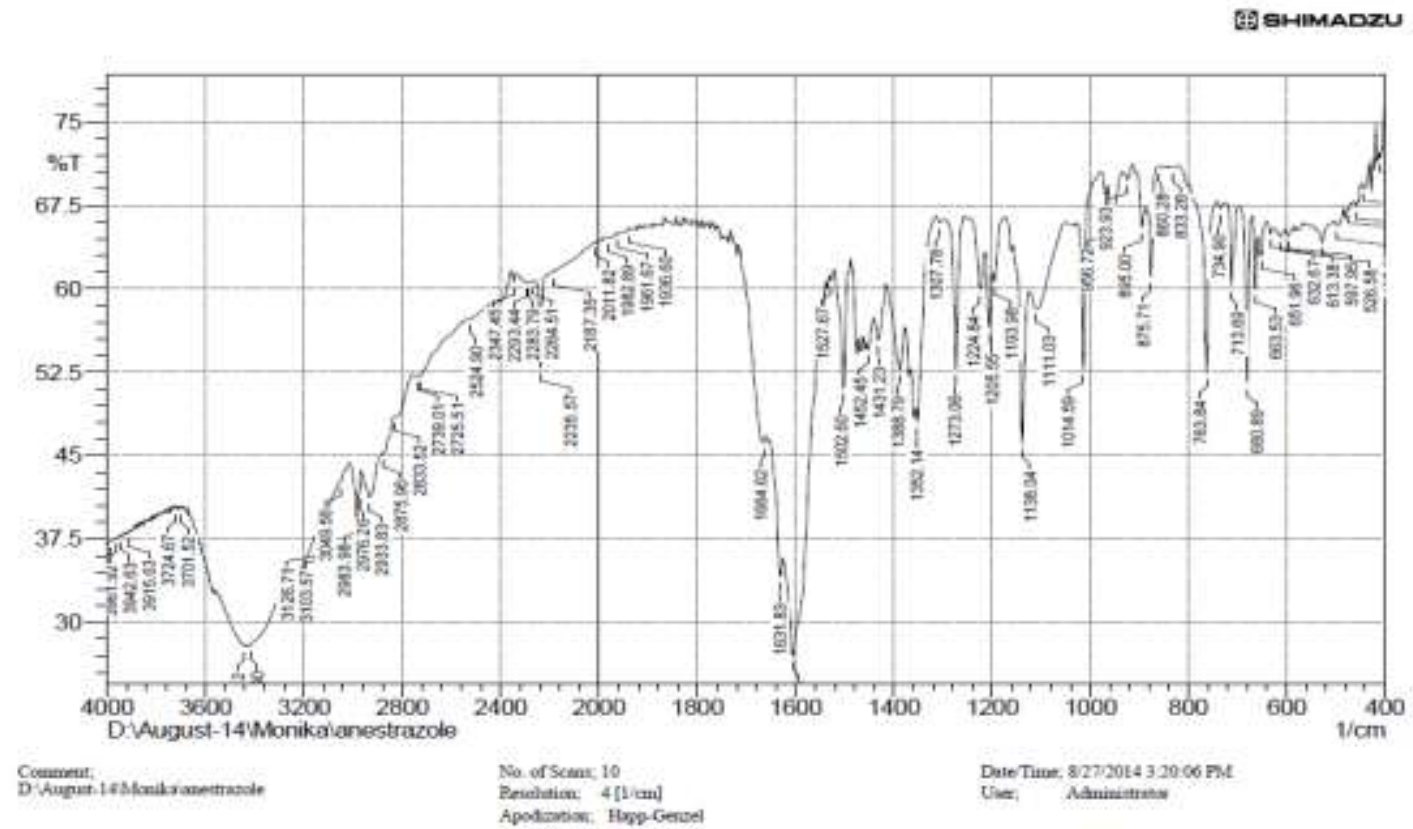

Figure no: 7 FTIR graph of anastrazole drug 


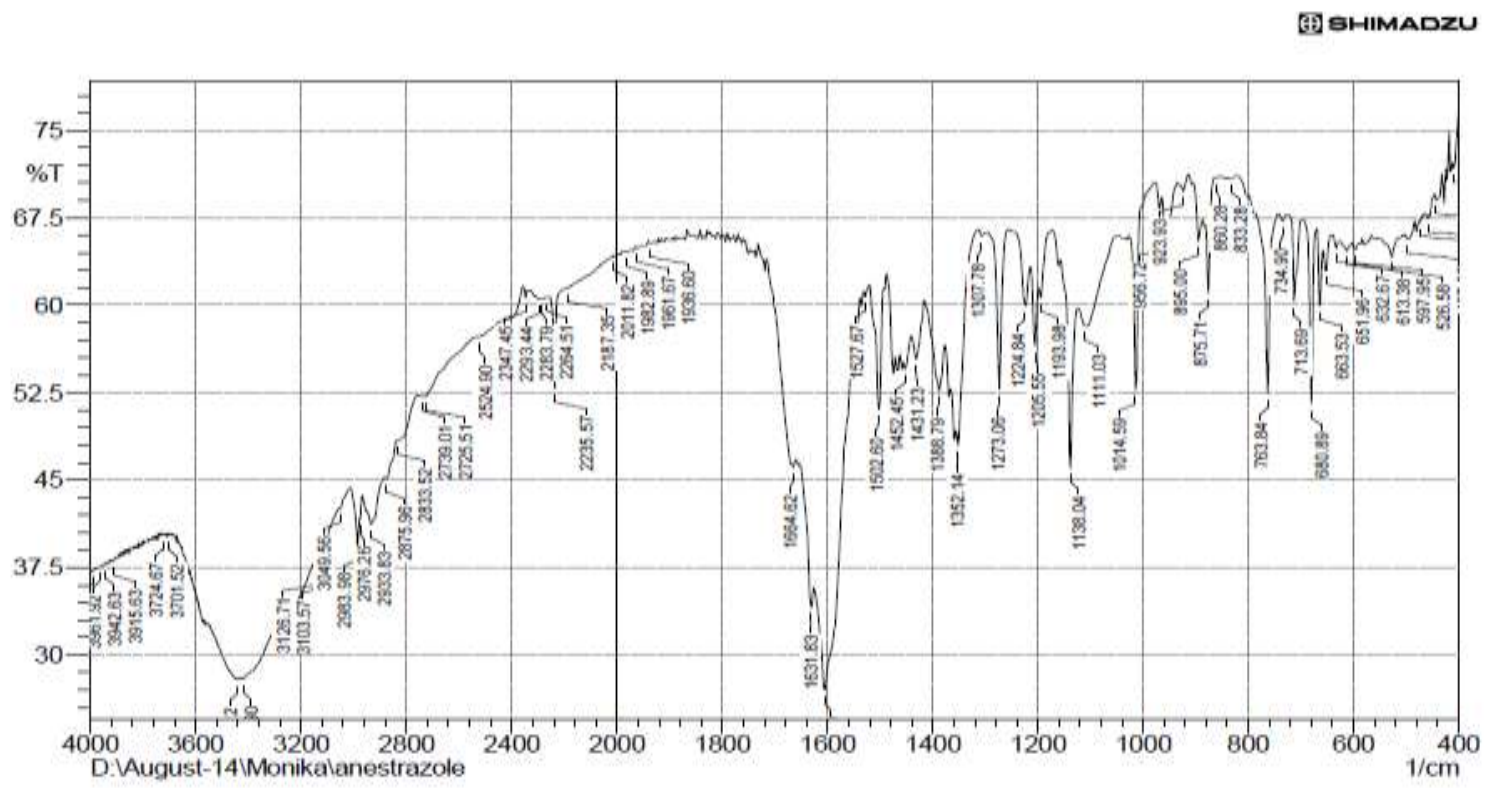

Figure no: 8 FTIR graph of anastrazole nanosuspension (F6)

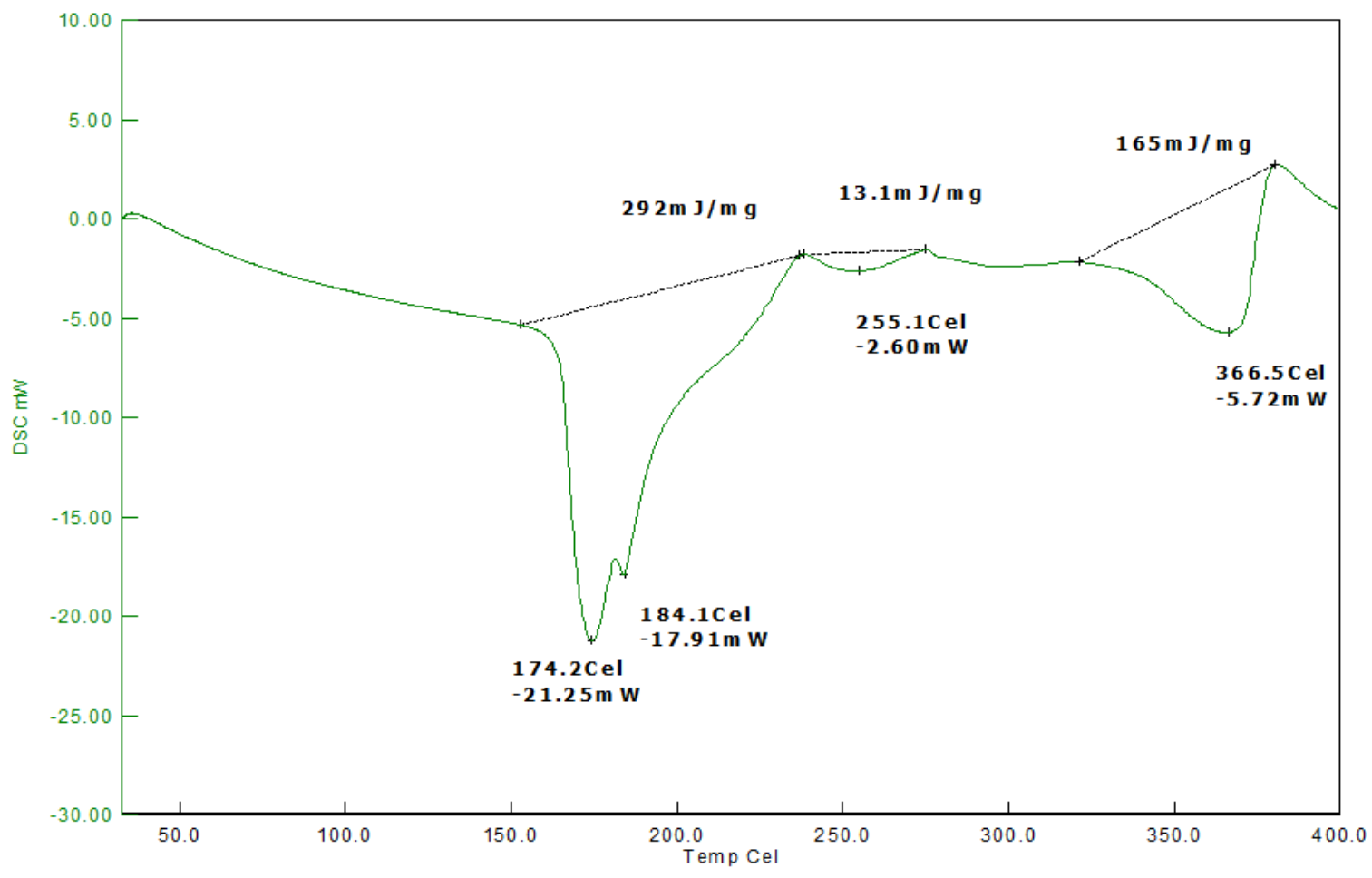

Figure no: 9 DSC graph of anastrazole drug 


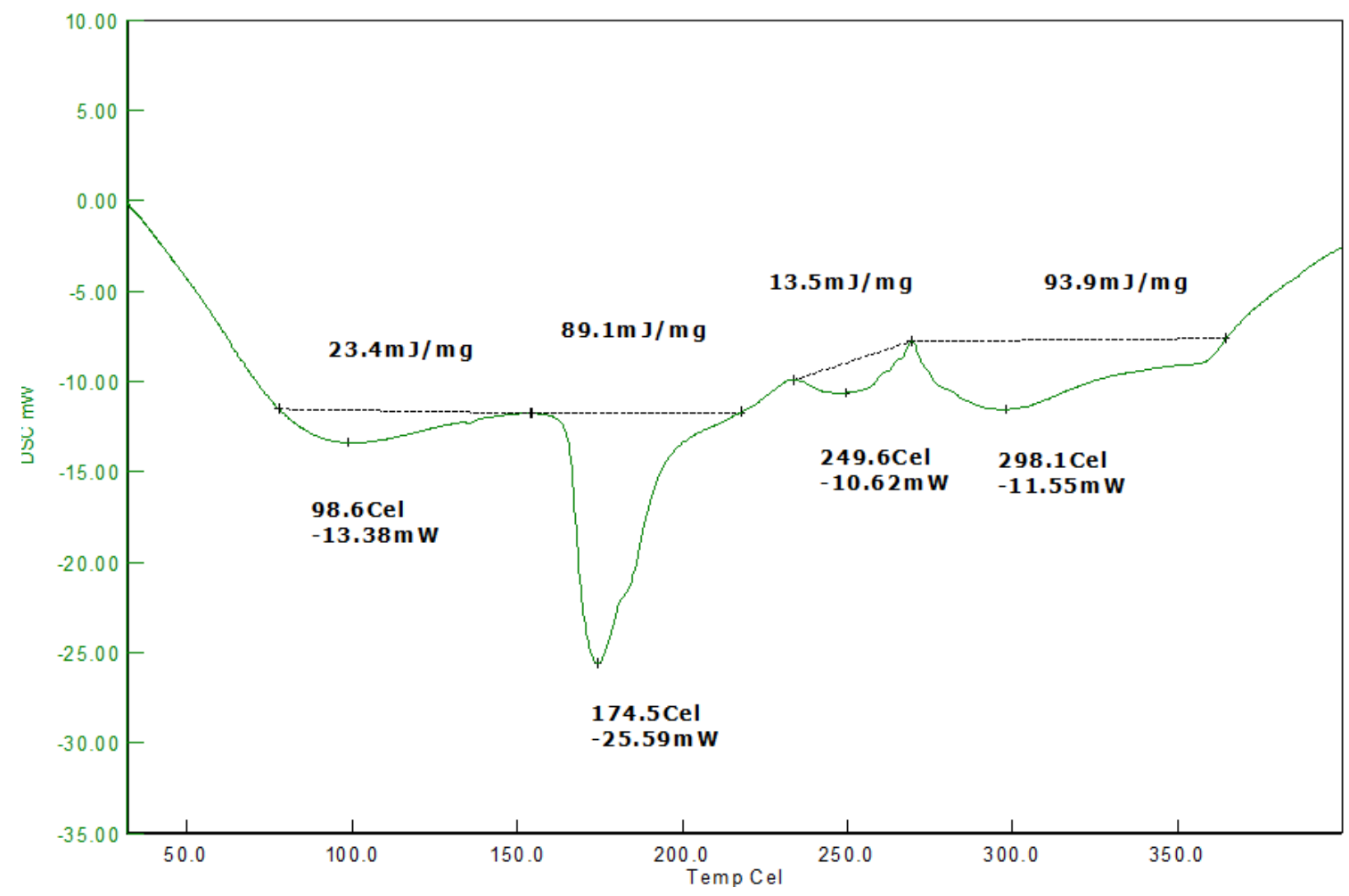

Figure no: 10 DSC graph of anastrazole nanosuspension (F6)

Table no: 3 Dissolution profile of nanosuspension formulations of F1-F8 formulations

\begin{tabular}{|l|l|l|l|l|l|l|l|l|}
\hline TIME(hours) & F1 & F2 & F3 & F4 & F5 & F6 & F7 & F8 \\
\hline 0 & 0 & 0 & 0 & 0 & 0 & $\mathbf{0}$ & 0 & 0 \\
\hline 0.25 & 2.3 & 2.5 & 2.4 & 2.6 & 2.2 & $\mathbf{3 . 2}$ & 3.45 & 2.1 \\
\hline 0.75 & 15.4 & 18.4 & 19.2 & 20.1 & 19.8 & $\mathbf{2 0 . 2}$ & 25.2 & 15.6 \\
\hline 1 & 28.4 & 29.3 & 24.2 & 26.3 & 27.1 & $\mathbf{3 0 . 5}$ & 38.23 & 33.2 \\
\hline 2 & 33.2 & 34.3 & 36.7 & 39.2 & 48.3 & $\mathbf{3 8 . 9}$ & 47.12 & 49.3 \\
\hline 3 & 36.7 & 35.8 & 46.8 & 49.4 & 49.3 & $\mathbf{4 8 . 8}$ & 53.14 & 46.9 \\
\hline 4 & 42.3 & 48.9 & 52.1 & 53.4 & 59.9 & $\mathbf{5 8 . 9}$ & 56.2 & 54.4 \\
\hline 5 & 57.8 & 53.9 & 57.6 & 63.8 & 64.2 & $\mathbf{6 5 . 4}$ & 68.7 & 66.5 \\
\hline 6 & 64.2 & 68.4 & 71.1 & 73.2 & 74.3 & $\mathbf{7 6 . 8}$ & 73.2 & 74.4 \\
\hline 8 & 70.21 & 77.47 & 75.64 & 78.12 & 79.21 & $\mathbf{8 1 . 7 6}$ & 79.99 & 80.23 \\
\hline 10 & 74.65 & 82.63 & 87.82 & 86.73 & 88.63 & $\mathbf{8 9 . 3 4}$ & 84.12 & 89.47 \\
\hline 12 & 80.85 & 86.45 & 89.97 & 90.79 & 91.23 & $\mathbf{9 4 . 3 6}$ & 90.45 & 91.12 \\
\hline 24 & 89.34 & 91.56 & 93.98 & 93.99 & 95.21 & $\mathbf{9 9 . 2 5}$ & 91.23 & 94.32 \\
\hline
\end{tabular}




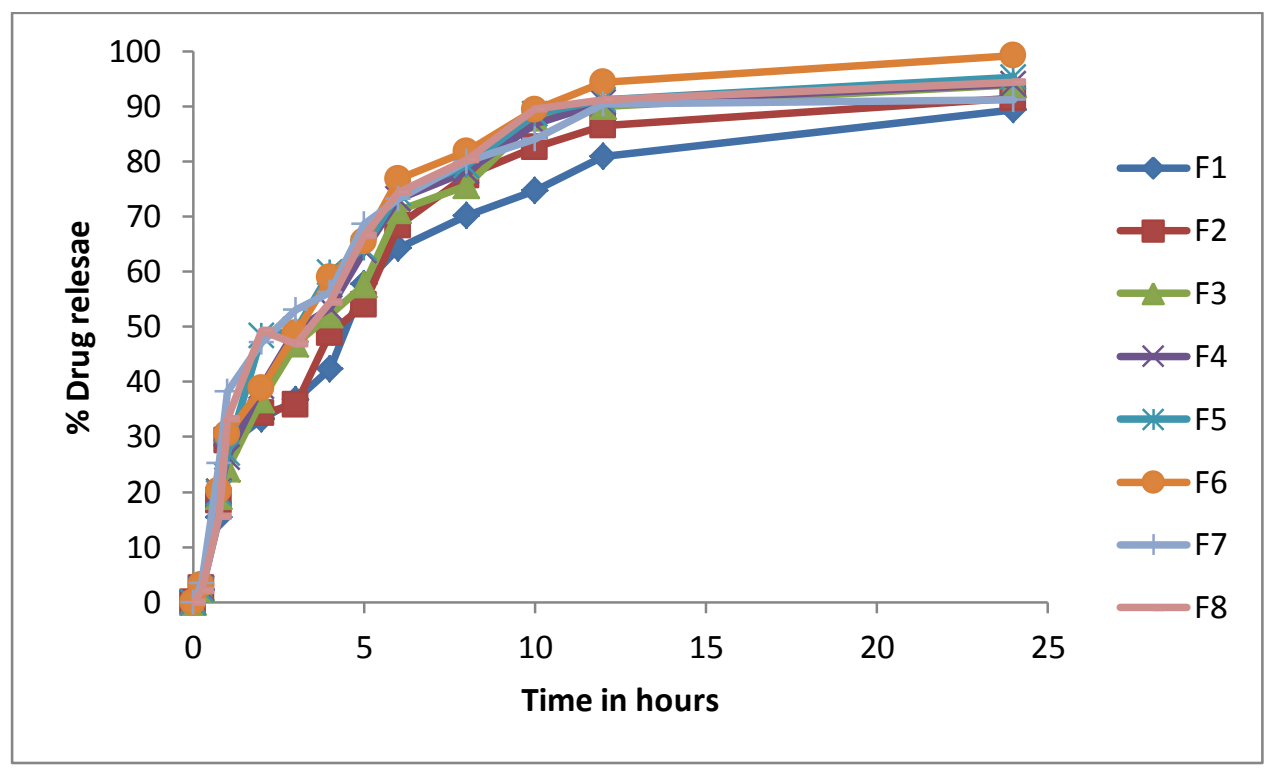

Figure no: 11 Graphical representation of dissolution profile of nanosuspension formulations of F1-F8

\section{Conclusion}

The preparation of parenteral nanosuspension for anastrazole was successfully prepared by solventantisolvent precipitation method. The whole of the eight nanosuspension formulations were determined for average particle size and saturation solubility. The optimum formulation based on less particle size and increased saturation solubility was selected. The nanosuspension (F-6) formulation has an average particle size of $0.345 \mu$ and saturation solubility was found to be $3.9 \mu \mathrm{g} / \mathrm{ml}$. The optimized sustained release nanosuspension formulation was characterized by SEM, zeta potential and XRPD studies. It is further evaluated for in vitro drug release rate studies. The particles surface of Anastrazole nanosuspension was spherical in shape. In particle size analysis, Anastrazole nanosuspension obtained comparatively nanonized particles range in $96 \mathrm{~nm}-190 \mathrm{~nm}$. The $24^{\text {th }}$ hour percentage drug release of optimized nanosuspension formulation was found to be $78.8 \%$. XRPD studies showed that the peaks obtained for pure drug is very clear and sharp the intensity of peaks are very high when compared to peaks of optimized Anastrazole nanosuspension formulation. Reduction in the peak indicates the changes in the crystal structure. From this we can conclude that there was reduction in crystallinity and change into amorphous structure. Therefore, in this study a parenterals controlled release of Anastrazole nanosuspension formulation of Anastrazole was successfully developed. The formulation is intended for controlled release delivery of the drug after i.v. administration with enhanced $\mathrm{C}_{\max }$. Hence it is good for breast cancer. The formulation can be good for adjuvant treatment of hormone receptor positive breast cancer, as well as hormonal treatment of advanced breast cancer in post-menopausal women because of the natural tendency of nanosuspension to be taken up into systemic circulation after intravenous administration.

\section{Acknowledgements}

The authors would like to acknowledge management of mother teresa college of pharmacy for providing necessary support to the conduction of this work. Also, the authors would like to acknowledge Department of technology, Osmania university, Hyderabad and R\&D cell, pharmacy department of JNTUH for providing analytical support to this project.

\section{References}

1. A Prameela Rani, P Sivannarayana, K Abbulu, and V Saikishore (2014). Design and Characterization of Anastrazole loaded chitosan nanoparticles by ionotropic gelation method. Research Journal of Pharmaceutical, Biological and Chemical Sciences, 5(3), 2069-2078. 
2. A. Prameela Rani, P. Sivannarayana, K. Abbulu, V. Saikishore (2014) Design and optimisation of anastrazole loaded chitosan nanoparticles by emulsification crosslinking and ionotropic gelation methods, Journal of Global Trends in Pharmaceutical Sciences, 5(2), 1719 -1725.

3. Ch. Prabhakara (2011). Review on nanosuspensions in drug delivery Nanotechnology. International Journal of Pharma and Bio Sciences, 2(1), 549-558.

4. Greeshma, V. Patel, Vaibhav B. Patel, AbhishekPathak, and Sadhana J. Rajput (2013). Nanosuspension of efavirenz for improved oral bioavailability: formulation optimization, in vitro, in situ and in vivo evaluation. Drug Development and Industrial Pharmacy, 40, 80-91. doi:10.3109/03639045.2012.746362.

5. Ghosh, I., Schenck, D., Bose, S., \& Ruegger, C., \& the IndrajitGhosh et al. (2012). Optimisation of formulation and process parameters for the production of nanosuspension by wet media milling technique: Effect of vitamin E TPGS and nanocrystal particle size on oral absorption. European Journal of Pharmaceutics, 47(4), 718-728. doi:10.1016/j.ejps.2012.08.011.

6. Dolenc, A., Kristl, J., Baumgartner, S., \& Planinšek, O. (2009, July). Advantages of celecoxib nanosuspension formulation and transformation into tablets. International Journal of Pharmaceutics, 376, 204-212. doi:10.1016/j.ijpharm.2009.04.038.

7. Kakran, M., Sahoo, N. G., Li, L., Judeh, Z., Wang, Y., Chong, K., \& Loh, L. (2010). Fabrication of drug nanoparticles by evaporative precipitation of nanosuspension. International Journal of Pharmaceutics, 383(1-2), 285-292. doi:10.1016/j.ijpharm.2009.09.030.

8. Liu, P., Rong, X., Laru, J., van Veen, B., Kiesvaara, J., Hirvonen, J., \& Peltonen, L., (2011). Nanosuspensions of poorly soluble drugs: Preparation and development by wet milling. International Journal of Pharmaceutics, 411(1-2), 215-222. doi:10.1016/j.ijpharm.2011.03.050.

9. Wang, L., Liu, Z., Liu, D., Liu, C., Juan, Z., \& Zhang, N. (2011). Docetaxel-loaded-lipid-basednanosuspensions (DTX-LNS): Preparation, pharmacokinetics, tissue distribution and antitumor activity. International Journal of Pharmaceutics, 413(1-2), 194-201. doi:10.1016/j.ijpharm.2011.04.023.

10. Verma, S., Kumar, S., Gokhale, R., \& Burgess, D. J. (2011). Physical stability of nanosuspensions: Investigation of the role of stabilizers on Ostwald ripening. International Journal of Pharmaceutics, 406(1-2), 145-152. doi:10.1016/j.ijpharm.2010.12.027.

11. Pardeike, J., Strohmeier, D. M., Schrodl, N., Voura, C., Gruber, M., Khinast, J. G., \& Zimmer, A. (2011). Nanosuspensions as advanced printing ink for accurate dosing of poorly soluble drugs in personalized medicines. International Journal of Pharmaceutics, 420(1), 93-100. doi:10.1016/j.ijpharm.2011.08.033.

12. Ghosh, I., Bose, S., Vippagunta, R., \& Harmon, F., \& the IndrajitGhosh. (2011). Nanosuspension for improving the bioavailability of a poorly soluble drug and screening of stabilizing agents to inhibit crystal growth, International Journal of Pharmaceutics, 409(1-2), 260-268. doi:10.1016/j.ijpharm.2011.02.051.

13. Mou, D., Chen, H., Wan, J., Xu, H., \& Yang, X. (2011). Potent dried drug nanosuspensions for oral bioavailability enhancement of poorly soluble drugs with $\mathrm{pH}$-dependent solubility. International Journal of Pharmaceutics, 413(1-2), 237-244. doi:10.1016/j.ijpharm.2011.04.034.

14. Mishra P.R., Al Shaal L., Müller R.H., and Keck C.M. (2009). Production and characterization of Hesperetinnanosuspensions for dermal delivery. International Journal of Pharmaceutics, 371(1-2), 182189. doi:10.1016/j.ijpharm.2008.12.030.

15. Mauludin, R., Müller, R. H., \& Keck, C. M., \& the RachmatMauludin and Rainer H. Muller. (2009). Development of an oral rutinnanocrystal formulation. International Journal of Pharmaceutics, 370(1-2), 202-209. doi:10.1016/j.ijpharm.2008.11.029.

16. Koteshwara, K. B., (2011). Nanosuspensions: A novel drug delivery approach. IJRAP, 2(1), 162-165.

17. Li, W., Yang, Y., Tian, Y., Xu, X., Chen, Y., Mu, L., \& Fang, L. (2011). Preparation and in vitro/in vivo evaluation of revaprazan hydrochloride nanosuspension. International Journal of Pharmaceutics, 408(12), 157-162. doi:10.1016/j.ijpharm.2011.01.059.

18. Detroja, C. (2011). Enhanced Antihypertensive Activity of Candesartan Cilexetil Nanosuspension: Formulation, Characterization and Pharmacodynamic Study. Scientia Pharmaceutica, 79(3), 635-651. doi:10.3797/scipharm.1103-17. 
19. Van de Ven, H., Paulussen, C., Feijens, P. B., Matheeussen, A., Rombaut, P., Kayaert, P., \& Ludwig, A. (2012). PLGA nanoparticles and nanosuspensions with amphotericin B: Potent in vitro and in vivo alternatives to Fungizone and AmBisome. Journal of Controlled Release, 161(3), 795-803. doi:10.1016/j.jconrel.2012.05.037.

20. Ghosh, I., Schenck, D., Bose, S., \& Ruegger, C. (2012). Optimisation of formulation and process parameters for the production of nanosuspension by wet media milling technique: Effect of vitamin $\mathrm{E}$ TPGS and nanocrystal particle size on oral absorption. European journal of Pharmaceutics, 47(4), 718728. doi:10.1016/j.ejps.2012.08.011.

21. Kocbek, P., Baumgartner, S., \& Kristl, J. (2006). Preparation and evaluation of nanosuspensions for enhancing the dissolution of poorly soluble drugs. International Journal of Pharmaceutics, 312(1-2), 179-186. doi:10.1016/j.ijpharm.2006.01.008.

22. Liu, P., Rong, X., Laru, J., van Veen, B., Kiesvaara, J., Hirvonen, J., Laaksonen T. \& Peltonen, L., (2011). Nanosuspensions of poorly soluble drugs: Preparation and development by wet milling. International Journal of Pharmaceutics, 411(1-2), 215-222. doi:10.1016/j.ijpharm.2011.03.050.

23. Agrawal, Y. K., \& Patel, V. R. (2011). Nanosuspension: An approach to enhance solubility of drugs. Journal of Advanced Pharmaceutical Technology \& Research, 2(2), 81-87. doi:10.4103/2231$\underline{4040.82950 .}$.

24. Dolenc, A., Kristl, J., Baumgartner, S., \& Planinšek, O. (2009). Advantages of celecoxibnanosuspension formulation and transformation into tablets. International Journal of Pharmaceutics, 376, 204-212. doi:10.1016/j.ijpharm.2009.04.038. 